\title{
ENTRE O LIBERALISMO DE DWORKIN E O GARANTISMO DE LUIGI FERRAJOLI - APROXIMAÇÓES E DIVERGÊNCIAS TEÓRICAS
}

\author{
BETWEEN THE LIBERALISM OF DWORKIN AND THE \\ GARANTISMO OF LUIGI FERRAJOLI - THEORETICAL \\ APPROXIMATIONS AND DIVERGENCES
}

\author{
ITALO FARIAS BRAGA ${ }^{1}$ \\ NATÉRCIA SAMPAIO SIQUEIRA ${ }^{2}$
}

\section{RESUMO}

O presente trabalho se propõe a comparar dois modos diversos de compreensão do direito, sob o propósito de assinalar suas aproximações e dessemelhanças e, com isto, melhor depurar a descrição da prática jurídica. Para tanto, investiu-se na análise comparativa doutrinária entre a teoria de Dworkin e Ferrajoli, tanto porque se mostram muito atrativas ao direito contemporâneo, como porque implicam diferente forma de concepção do direito com pretensa herança do positivismo e jusnaturalismo. Mediante pesquisa bibliográfica, expõe-se, a um primeiro momento, a teoria de Dworkin, para depois abordar a de Ferrajoli. Num terceiro momento, analisa-se de forma comparativa ambas as abordagens e conclui-se pela aproximação prática de uma e de outra, pois nestes modos teóricos se possibilitam o diálogo entre direito e moral. Não obstante, do diferente discurso sobre a relação entre direito e moral resultam diferentes possibilidades ao direito e à moral no âmbito de cada uma delas.

Palavras-chave: Liberalismo. Luigi Ferrajoli. Ronaldo Dworkin. Direito e moral. Análise comparativa.

\section{ABSTRACT}

The present review proposes compare two different ways of understanding the law, in order to point out their approximations and dissimilarities and with this, better debug the discretion of the legal practice. In order to do so, it was invested in the comparative analysis between Dworkin's theory and Ferrajoli's, both because

1 Doutorando em direito constitucional pela Universidade de Fortaleza. Mestre em direito pela Universidade de Fortaleza. Pesquisador do laboratório de ciências criminais da Universidade de Fortaleza. Professor do Centro universitário Farias e do Centro universitário Uninassau. Advogado. ORCID iD: https://orcid.org/0000-0002-7351-8498. E-mail: italofbraga@ gmail.com.

2 Doutora em Direito pela Universidade de Fortaleza. Professora Titular do Programa de Pós-Graduação Stricto Sensu em Direito Constitucional da Universidade de Fortaleza. Procuradora Fiscal da Procuradoria Geral do Município de Fortaleza. naterciasiqueira@yahoo.com.br. 
they are very attractive to contemporary law, and because they imply different forms of conception of law with a supposed inheritance of positivism and jusnaturalism. For this, through a bibliographical research, the Dworkin theory was expose, at a first moment, to later address the one of Ferrajoli. In a third moment, the comparative analysis between the two is carried out and it concludes by the practical approximation of one and the other, because in both the dialogue between law and morality is possible. Nevertheless, from the different discourse on the relation between law and morality, there are different possibilities for the right and the moral in each of them.

Keywords: Liberalism. Luigi Ferrajoli. Ronaldo Dworkin. Right and moral. Comparative analysis.

\section{INTRODUÇÃO}

A justiça constitui tema recorrente na filosofia e no direito ao longo da história da humanidade. Assim, no percurso temporal, questões aporéticas, tais quais a liberdade e a igualdade, constituíram o arcabouço de amplas discussões aos juristas contemporâneos, que se inspiram em fontes como o jusnaturalismo, o juspostivismo e as próprias interfaces entre o direito a moral. Assim, a concepção de direito e justiça é enfrentada de forma própria por Ronald Dworkin e por Luigi Ferrajoli.

O interesse acadêmico na análise das teorias desses autores justifica-se pelo fato de terem impactado as compreensões de direito e os rumos tomados pelas cortes em escala mundial. Por um lado, Dworkin foi - e ainda é - alicerce metodológico e teórico. Por outro, Ferrajoli apresenta uma teoria que se consolidou como fundamento das limitações do Estado em um modelo pós-positivista, cujas diretrizes também são tomadas em escala doutrinária. Assim, Dworkin e Ferrajoli representam facetas de ideias jurídicas que se contrapõem e se completam para a compreensão do direito justo.

Desta forma, ganha relevância a discussão sobre quais modelos de Estado de direito são suficientes para garantir a melhor segurança jurídica, frente as limitações das separações entre direito e moral, frente as visões liberais de mundo. Sobretudo, tem-se nas discussões a necessidade de garantir a compreensibilidade de um direito justo, pela segurança jurídica da lei liberal e que seja efetivo para lidar com os problemas causados pelo positivismo clássico.

Deste modo, restam questionamentos como quais seriam os modelos decisórios propostos por Ronald Dworkin e por Luigi Ferrajoli para lidar com o problema do bem decidir, frente os paradigmas liberais de igualdade dos autores?

O objetivo deste trabalho, passa a ser então compreender a sistemática de pensamento de Ronald Dworkin e posteriormente a teoria de Luigi Ferrajoli, diante do contexto da moral de liberdade e igualdade e da aplicabilidade do direito justo, mediante a segurança jurídica frente os problemas do juspositivismo.

Referidos autores investem em discursos metodológicos diferentes para explicarem o direito, que se têm mostrado paradigmáticos: o discurso positivista, de um lado, e o discurso hermenêutico, de outro. De outra sorte, as diferentes metodologias propostas para a prática jurídica implicam diferentes teorias sobre a relação entre o direito e a moral. Neste panorama, o presente artigo se dedica à análise comparativa das duas concepções do direito, a de 
Ferrajoli e a de Dworkin, com o propósito de lhes ressaltar as semelhanças e as diferenças, de maneira a tornar-lhes mais nítidas em seus contornos.

Uma vez que este trabalho propõe a análise comparativa entre dois pensadores e suas concepções do direito, ele apresenta cunho eminentemente bibliográfico. Nesta toada, o presente estudo aborda, inicialmente, a teoria de Ronald Dworkin, sobretudo o modelo liberal adotado que se realizaria, elementarmente, pela neutralidade oficial axiológica como contenção do Estado. Em seguida, analisa-se a teoria do garantismo com os pressupostos de Luigi Ferrajoli, que a apresenta como teoria geral do direito numa roupagem neo-positivista que seria a adequada ao neo-constitucionalismo.

Em um terceiro momento, comparam-se as concepções de Ferrajoli e de Dworkin, de modo a buscar aproximações e divergências entre si. Ao final, conclui-se que não obstante diferentes sejam os discursos metodológicos, na prática, o pós-positivismo de Ferrajoli se aproxima da teoria Dworkiana, uma vez que possibilita um intenso diálogo entre direito e moral mediante o esforço argumentativo. Não obstante, referida constatação gera dupla advertência: a) ainda que se abstraia do discurso e se foque na prática, a diferença no tratamento da relação entre moral e direito pelas duas teorias resulta em diferentes fundamentos últimos do direito, com implicações em algumas áreas, em especial no direito internacional; b) mesmo que nas duas teorias haja diferente ênfase na relevância da moral ao direito, em ambas se deve levar a filosofia a sério, de maneira que o direito não se converta em um caleidoscópio de opiniões sem fundamentação sólida.

\section{BASES TEÓRICAS DE RONALD DWORKIN}

A igualdade e a liberdade são temas fundamentais no arcabouço de análises de Ronald Dworkin (DWORKIN, 2000), que propõe um modelo liberal de Estado que se amolde a uma teoria de justiça cuja base axiológica se compromete com o conteúdo da igualdade: as pessoas são iguais à medida que o Estado trata com igual consideração os vários modelos e escolhas de vida. Dessa forma, liberdade e igualdade, como conteúdo da justiça, implicariam limitações materiais e discursivas ao Estado, mas também demandariam a assunção de deveres por particulares e pelo Ente público para assegurar a igualdade de recursos equalização das diferenças do meio e pessoais de forma que todos tenham oportunidades equitativas de se desenvolverem dentro de suas escolhas.

Vai-se além: para as teorias liberais, sejam elas constituídas pelos clássicos, como Locke, Kant, Mill ou pelos contemporâneos, como Dworkin, Ralws e mesmo Ferrajoli, as restrições à liberdade só se enquadram num ordenamento jurídico pretensamente democrático mediante justificativa plausível, racional e legítima. Nesse sentido, Dworkin estaria a propor um modelo de liberdade ao qual seria condição elementar a neutralidade axiológica do Estado, que implica abstenções, mas também atuações, com o intuito de se possibilitar o exercício das formulações pessoais de cada indivíduo. (IOSA, 2017).

Desta feita, os limites para a intervenção estatal não são fruto exclusivo da pretensão jurídica, mas sobretudo da compreensão filosófica de que decorre a interpretação do direito. Assim, mesmo sob o viés positivista, aceitável por parte do pensamento liberal, ou por um 
pensamento de hermenêutica mais construído na visão jurisprudencial, a constituição filosófica impele o direito (MELO; POMPEU, 2017).

É importante, entretanto, não perder a perspectiva de que a pretensão de justificar a igual liberdade como parâmetro de limitação, mas também de informação e de orientação do Estado, depreende-se da concepção axiológica prévia de que cada ser humano é igual em dignidade e tem igual direito à busca equitativa pelo seu melhor quinhão pessoal, assim compreendido o conjunto de bens e direitos que melhor se adequam ao modelo de vida estabelecido por cada pessoa a si. Por ser igualmente digno a qualquer outro, cada qual pode optar pelo seu modelo de vida, sem que o Estado intervenha - significativamente; salvo, e daí retorna-se à advertência Kantiana, se as escolhas pessoais interferirem, direta e elementarmente, na liberdade do outro que é igualmente digno.

Liberdade e igualdade expressam facetas da tutela formal e material pelo Estado, que não se realizam, conforme já se advertiu, pela não intervenção ou abstração do Estado de impor ou induzir algum modelo de vida boa para todos. Igualdade e liberdade constituiriam modelos de sociedade nos quais se permite o aquinhoamento de bens, que são função das concepções de vida adequadas aos anseios pessoais de seres humanos igualmente dignos, de modo formal e material (FACHIN; SCHAUMAN, 2008).

Para justificar o conteúdo material que atribui à igualdade, como igual sistema de liberdades que garantam o exercício da autonomia individual, Dworkin desenvolve a "metáfora" do leilão na ilha deserta. Assim, descreve uma fábula que trata do problema da divisão dos bens em uma ilha entre os náufragos (DWORKIN, 2005). Para testar a justiça do método de distribuição, faz uma série de proposições: primeiro, sugere que se realize a distribuição igualitária dos bens. Nesse caso, conclui pela injustiça do método, uma vez que resultaria em um quinhão imerecidamente grande a quem não o merece, bem como implicaria má distribuição dos recursos escassos, visto que imporia um quinhão de bem específico aos náufragos que, por esta condição, não satisfaria de forma adequada os interesses pessoais de cada qual. Referida metodologia de distribuição não passaria pelo teste da cobiça (DWORKIN, 2005, p. 81), razão pela qual a divisão mecânica dos recursos seria insuficiente para estabelecer um padrão de igualdade qualificado pela liberdade e autonomia dos indivíduos.

Propõe então um outro método: a distribuição de igual quantidade de fichas aos náufragos para a realização de uma dinâmica similar a um leilão. Esta sistemática pretende revelar o mercado como instrumento "justo" para distribuição de bens econômicos, dado que cada pessoa gastaria as suas fichas numa estratégia pessoal de planos de vida; ou seja, ao limite que Ihes traga satisfação pessoal. Neste sistema hipoteticamente justo, deixar-se-ia cada pessoa igualmente livre e responsável para aquinhoar os seus bens, mas sob o custo da soma das escolhas pessoais. (DWORKIN, 2005).

O mercado, portanto, respeitaria a axiologia "prévia" pautada na igualdade de liberdade e responsabilidade. Isto porque um sistema de distribuição de riquezas na sociedade revela-se justo à medida que formatado por uma mecânica que permita que as pessoas sejam igualmente livres e responsáveis pela sua sina. Por palavras sintéticas: o leilão, como metáfora do mercado, revela-se justo como método de distribuição de bens, uma vez que igualmente respeita os diversos modelos de vida ao atribuir a cada qual igual liberdade, recursos e responsabilidade para amealhar o seu quinhão de bem sem implicar, portanto, uma construção homogeneizadora ou ditatorial (MONTARROYOS, 2013). 
A preocupação com a igualdade como referencial do direito é máxima que extrapola as concepções de Dworkin. Tem-se a igualdade, ou pelo menos a não desigualdade absoluta, respeitados os modos de vida, como parâmetro essencial para um critério democrático e sobretudo para um critério de aplicação do direito justo (MARCO, SANTOS, MOELLER, 2019).

Assim, tem-se na teoria de Dworkin os fundamentos ou justificativas axiológicas de institutos sociais, o que se dá ao se mostrarem conforme os condicionamentos formais e materiais da justiça. É fato que, fora do plano hipotético, as questões de desenvolver e aprimorar instrumentos e mecanismos que observem os condicionamentos da justiça adquirem grande complexidade. No entanto, para efeitos deste trabalho, o que se quer é ressaltar a metodologia dworkiana de averiguação da justiça de métodos de distribuição de bens sociais através da respectiva conformidade aos condicionamentos da igual dignidade da individualidade.

Mas além do justo critério de distribuição de bens econômicos, Dworkin igualmente se aventura pelo justo critério de distribuição de direitos. Esse seria a democracia representativa (DWORKIN, 2000, p. 288), que estaria limitada e condicionada pela prévia axiologia da igualdade, tanto referente à economia, como às outras áreas de regulação, tais quais direitos civis e bioética. Dworkin, dessa forma, mantém a tensão entre a concepção de direitos fundamentais e democracia: processo democrático seria justo na medida em que fossem igualmente respeitadas as várias individualidades, de modo a se garantir a igual dignidade aos diferentes modelos de vida (VIRGÜEZ RUIZ, 2015).

Nesse sentido, o conceito dworkiano implica que a democracia, per si, não seria suficiente para constituir um modelo justo. Entretanto, um modelo justo não poderia não ser democrático. Isto é, um modelo justo depende da concepção democrática de que as vontades pessoais têm igual peso e relevância, tanto nas relações econômicas como políticas. Assim, a interferência do Estado se legitima tanto no processo democrático como na axiologia que the é anterior e basilar: a igual autonomia individual como limite integrador do direito, que não se mostra incompatível com decisionismos lastreados em padrões morais de concepções específicas de modelos de vida (KYRITSIS, 2016).

Assim, Dworkin apresenta uma crítica ao positivismo, lançando mão do paradigma da interpretação, de modo que a estrutura positivista não seria a única a moldar o direito (RODRIGUES, 2013). Entretanto, mesmo diante da aplicação teórica em que o positivismo estaria estruturalmente equivocado, Dworkin não afasta a legislação e as decisões mediante modelos cooperativos de direito com segurança jurídica.

Dworkin ainda propõe a distinção entre modelo majoritário e cooperativo. 0 modelo majoritário seria aquele no qual a simples decisão da maioria seria suficiente para interferir na liberdade da minoria, inclusive da maior minoria possível, seja ela o indivíduo. Já um modelo cooperativo, ou de parcerias, compreende que, por mais que exista a possibilidade de atuação conjunta e a interferência em razão de valores públicos, há de se respeitar os modos de vida e a axiologia que prevê igual dignidade entre seres humanos. Somente mediante um sistema cooperativo de parcerias seria viável uma constituição justa, e, portanto, seria racional a interferência na autonomia individual (GOODHEART, 2013).

Um modelo interpretativo liberal e justo não descartaria, portanto, a legalidade, o que poderia sugerir uma aproximação com o positivismo. Entretanto, o recorte da legalidade não quer dizer que a interpretação literal seja a única possível, pelo contrário, as bases legais são 
postas e interpretadas mediante o elemento axiológico que serve como liga integradora do direito: a igual dignidade das individualidades. 0 direito, para Dworkin, não se realiza numa prática de enquadramento semântico que se realizaria pela respectiva descrição fática. Antes, a prática jurídica seria interpretativa, dar-se-ia no esforço de argumentação mediante considerações coerentes a partir de um eixo de valor comum. Antes de o direito encontrar numa estrutura metodológica funcional e apriorística a sua legitimidade e validação, ele se legitimaria pela construção de uma interpretação séria, que antes de se aventurar pela descrição fática de como acontece, propõe-se a se apresentar nas suas melhores luzes.

\section{O GARANTISMO JURÍDICO}

A teoria do garantismo surge como teoria jurídica estruturante para a formulação de uma teoria geral do direito e como parâmetro de justiça pós-positivista. Dessa forma, traz à baila a validade das normas jurídicas e os vetores de aplicação normativos, de modo que é indispensável a conceituação teórica das ideias de Ferrajoli para estabelecer o arcabouço epistemológico sobre o qual, significativamente, repousa o direito contemporâneo.

Ademais, neste trabalho verifica-se que o garantismo, na órbita do direito interno, como reflexo de uma teoria liberal, conversa com a teoria de Dworkin, o que levaria a uma observação preliminar de que ela não seria incompatível com a lógica garantista. Entretanto, a verificação prévia não é de contrariedade de ideias, de modo que os modelos de Ronald Dworkin e Luigi Ferrajoli se complementam na compressão da melhor aplicação do direito.

\subsection{A TEORIA GERAL DO GARANTISMO JURÍDICO}

A teoria do garantismo, tal qual proposta por Luigi Ferrajoli, constitui um espectro de ideias vinculado ao tronco de teorias sobre o direito que têm por parâmetro a legalidade e a proteção das liberdades individuais. Em que pese existir razoável deturpação dos conceitos garantistas vinculados ao senso comum, até mesmo de forma pejorativa em razão dos movimentos ligados a grupos protetores de direitos humanos, deve-se compreender aquilo que efetivamente as teorias garantistas implicam.

No plano etimológico a palavra garantismo origina-se do conjunto de línguas neolatinas, de modo que trazia, nos textos primários, a ideia de tutela, proteção e salvaguarda aos mais fracos. Isto é, garantismo, inicialmente, significava a garantia à proteção. De início, estes termos foram vinculados aos países de cultura civil law, tais quais Itália, Portugal e até mesmo Brasil, e relacionados às liberdades negativas, ou seja, limitações do Estado pela lei (IPPOLITO, 2011). Frise-se que sequer há tradução antiga para garantismo ao inglês, que se utiliza da palavra "garantism", cuja construção foi totalmente trazida da doutrina romano-germânica.

Esse termo teve, com o advento do welfare state, ampliação semântica, de modo que não mais se limita a significar a garantia de proteção individual, ou limitação do arbítrio estatal. Antes, estendeu-se aos meios adequados à tutela efetiva daquilo que se pretendia 
como direito. Desta forma se impunha não apenas a proteção individual aos mais fracos, mas também a necessidade positiva de efetivação de uma matriz constitucional de proteção às liberdades individuais e de efetivação dos direitos sociais (IPPOLITO, 2011).

Luigi Ferrajoli, ao analisar a origem etiológica do termo, confere à palavra constitucionalismo (ou garantismo) três sentidos. Há de se mencionar que estes sentidos da palavra não se confundem com as dimensões descritas no livro Direito e Razão (FERRAJOLI, 2014), mas complementam a compreensão destas. O primeiro sentido estaria na palavra garantismo como "paleopositivismo", porque, para Ferrajoli, consubstanciaria a revisitação ao positivismo jurídico com viés de proteção material. A segunda interpretação do termo estaria vinculada às definições de validade e vigência, em relação às quais o garantismo implicaria a garantia de validade e vigência dentro de um modelo constitucional das normas entendidas como justas por aquela sociedade. Já a terceira acepção da palavra garantismo afigura-se no modelo de filosofia política, sob a qual estaria baseada uma teoria geral do direito em bases materiais para se definir, de forma democrática e legítima, como seria "um bom governo" (COSTA e VERAS NETO, 2016).

Portanto, extrai-se da etiologia do termo garantismo a ideia de garantia, efetivação, seguridade, defesa, preservação de indivíduos frente ao arbítrio estatal. Destarte, há no garantismo um modelo de direito e uma teoria geral pelos quais garante-se a liberdade individual por meio de um sistema de proteções e tutelas lastreado na legalidade e na constitucionalidade sob aspectos formais e materiais (AVILA, 2017).

As considerações de garantismo como uma teoria exclusiva ao direito penal ou processual penal são bastantes comuns na compreensão leiga. Entretanto, não há paralelo acadêmico de vinculação exclusiva de garantismo à esfera penal ou processual penal. Antes, as ideias de Ferrajoli tratam de uma teoria geral do direito por matizes filosóficas, já que, enquanto professor, dedica-se ao ensino das disciplinas de Teoria Geral do Direito e de Filosofia Analítica (FERRAJOLI, 2014).

Verifica-se, assim, a aplicação dos postulados garantistas em todos os ramos do direito. A título exemplificativo, Fredie Didier (2011, p. 211) trata da aplicabilidade da doutrina garantista no âmbito processual, abrangendo neste caso o processo civil. Dessa forma, é descrita a doutrina como aquela que teria por objetivo a proteção do cidadão frente aos abusos do Estado num modelo liberal de limitações. Assim, para Didier (DIDIER, 2011), o sistema garantista de processo deixa de trata-lo como mero duelo entre partes e o considera pela necessária conformação a primados, tais quais a garantia do contraditório, a necessidade do aprimoramento das decisões judiciais e, mesmo, a construção de uma teoria de argumentação baseada na legalidade cumulada com a efetividade material daqueles primados tidos por indispensáveis.

É bem verdade que no livro Direito e Razão de Luigi Ferrajoli (2014), trata-se diversas vezes de matéria ligada diretamente à área criminal material e processual. Entretanto, não é possível deduzir, diga-se uma vez mais, que o sistema dito garantista seja restrito a essas questões. 0 que se verifica é que, como uma teoria liberal lastreada nos conceitos de legalidade e plasmada pela prévia aspiração liberal de limitação do arbítrio estatal, Ferrajoli trabaIha uma axiologia aplicável com muita clareza ao direito penal, fonte de arbítrios de diversas naturezas e onde tradicionalmente se reforça o caráter silogístico. Portanto, as teorias de Ferrajoli constituíram base para refrear o punitivismo e se imiscuíram em pontos úteis às 
ciências criminais, à criminologia e ao próprio direito penal e processual penal (FREITAS, MANDARINO, ROSA, 2017).

A noção garantista posta-se, então, como uma teoria liberal de natureza eminentemente constitucional. Dessa forma, verifica-se que, para o garantismo, a tutela do cidadão deve ser aquela consubstanciada na não intervenção desnecessária do Estado, e isto em qualquer ramo jurídico, seja direito processual ou material, o que refreia - acredita-se - a imposição do modelo de vida ou lógica persecutória de cidadãos. Em suma, o garantismo seria um modelo liberal fundado na legalidade e constitucionalidade, sob o respeito das garantias fundamentais (SERETTI, 2009).

A estrutura do sistema garantista proposta por Luigi Ferrajoli para a proteção das liberdades individuais, com fundamento liberal, utiliza-se essencialmente da legalidade, mas sem desconsiderar os avanços constitucionais das tutelas positivas. Dessa forma, é formatado no sistema garantista a dupla face de respeito normativo ao texto constitucional. A primeira face manifesta-se na garantia de não intervenção desnecessária, ao passo que a segunda revela-se na necessidade de atuação positiva do Estado para a garantia daquilo definido como fundamental ao cidadão (CADEMARTORI; GRUBBA, 2012).

Por conseguinte, o sistema garantista define 3 (três) eixos estruturantes: o primeiro a consubstanciar-se na hierarquia material normativa da Constituição por uma dinâmica de "estrita legalidade" sob o plano epistemológico; o segundo a revelar-se como instância crítica do direito e da realidade, no qual se avalia a norma pela compatibilidade e pela efetividade, de modo a evitar decisões teratológicas com base em uma argumentação sólida; e o terceiro se aventura pela filosofia e crítica política, instâncias pelas quais se legitima ao direito a tutela das finalidades do Estado e nas quais se trabalham as características da sociedade democrática em sentido amplo, ou seja, sob o enfoque de que as vontades e decisões da maioria vigem, desde que a respeitar os limites mínimos das minorias (FERRAJOLI, 2014).

Alexandre Moraes da Rosa trata de quatro frentes ou dimensões do garantismo. i) A primeira frente é descrita como a necessidade de verificação de compatibilidade formal e material da norma à Constituição, primado hierárquico que deve ser cumprido por vinculação positiva; ii) a segunda dimensão dá-se na verificação de um sistema pelo imperativo da efetividade democrática. Nela, se assume que as normas devem ser legítimas, o que ocorre ao observar os direitos tidos como fundamentais; iii) a terceira frente se situaria na vinculação da atividade judicante ao direito, segundo a qual o magistrado guarda estrita sujeição às normas. Estaria, portanto, vinculado à legalidade e à constitucionalidade; iv) por fim, a quarta dimensão se ocuparia de trabalhar o senso crítico da ciência jurídica com o propósito de se evitar decisões teratológicas (ROSA, 2003).

Nessa senda, o garantismo implica uma teoria geral de direito, entendida como uma teoria democrática de justiça, aplicável aos diversos ramos do saber jurídico por ter caráter constitucional. O garantismo é a teoria que prega a conformação democrática de respeito ao texto constitucional. Dessa forma, os termos propostos por Luigi Ferrajoli (FERRAJOLI, 2014), ao formular os eixos estruturantes de condutas de teoria geral que vinculam o Poder Público, diferencia a mera validade e vigor das normas produzidas, ao passo que as classifica entre ilegítimas e juridicamente válidas. As normas só podem subsistir num sistema jurídico se adequadas materialmente a este. 
Portanto, é entendido o garantismo como o processo aplicável ao pós-positivismo constitucionalizado. Pretende a formulação garantista ser balizadora não apenas da decisão judicial, mas da própria formulação legislativa, ao estabelecer parâmetros de atuação do Estado lastreados na não intervenção e no cumprimento efetivo das disposições constitucionais. Ademais, para a teoria garantista, os princípios, como normas, deveriam positivar-se mesmo que representem axiologia prévia (FERRAJOLI, 2014).

Assim, para se ter um sistema democrático e por consequência mais próximo ao justo, seria necessário do plano epistemológico a separação entre 3 categorias: i) aquilo que pode ser decidido pela maioria; ii) aquilo que deve ser decidido pela maioria; iii) aquilo que não pode ser decidido pela maioria. Desta feita, o sistema jurídico é consolidado pelas limitações entre aquilo que não pode ser decidido pela maioria, por ferir garantias mínimas inerentes à condição humana, divergindo daquelas questões cujo interesse público predomina, de modo que nestas devem ser decididas pela maioria ou podem ser decididas pela maioria (FERRAJOLI, 2014).

Para tal é que se compreende a dimensão democrática do garantismo como o compartilhamento de poderes, no qual a adstrição de cada um à sua função permite a criação e a aplicação da norma de forma substancial, aqui entendida como aquela na qual as liberdades existem e são respeitadas não apenas no plano formal. Isto é, para o garantismo, o legislativo tem a sua função específica na dinâmica de funcionamento do Estado, que é circunscrita à decisão sobre aquilo que deve ser decidido - ou seja, sobre a criação de normas legítimas -, enquanto o judiciário tem o dever de aplicação legítima das normas produzidas pelo legislativo, o que faz mediante aplicação normativa crítica sob fundamentação racional (CADEMARTORI; CADEMARTORI, 2006). Portanto, em um sistema efetivamente democrático, nem sobre tudo se pode decidir, ao passo que as decisões são tomadas mediante o sistema de leis, especialmente da Constituição Federal, que limita os poderes do Estado.

Nesse contexto, a teoria garantista não afasta uma limitação axiológica prévia que seja lastreada, de certa forma, na moral. Apenas compreende que as garantias formuladas pela segurança do modelo liberal positivista não devem ser afastadas, constituindo sustentáculo para ser aplicado em conjunto com os princípios que se positivariam no sistema, à medida da necessidade de cada sociedade, de acordo com um processo legislativo moldado a partir de valores (ZANON JÚNIOR, 2015).

Portanto, o modelo garantista é aquele no qual o sistema de princípios é constitucionalizado. Investe na construção de um modelo formal de funcionamento, legitimação e validação do direito, mas o faz de forma arejada à moral, já que a aplicação das regras pode ser mitigada pela adoção de uma interpretação material principiológica, sob a preocupação crítica de se evitar a teratologia em suas decisões. 


\section{APROXIMAÇÓES E DIVERGÊNCIAS ENTRE LUIGI FERRAJOLI E RONALD DWORKIN}

Inicialmente deve-se dizer que Ferrajoli e Dworkin constituíram suas obras e suas ideias em correlações diferentes de espaço e mentalidade jurídicas. Dworkin voltou-se à escrita com base nos hard cases norte-americanos, de modo a buscar uma formulação de argumentações sérias para as decisões em um sistema tipicamente descrito de Common Law. Por outro, Ferrajoli desenvolveu suas teorias na Itália, envolto pelas teorias do Civil Law e posteriormente a longos períodos de baixa estabilidade na península itálica.

É perceptível que ambos os autores fazem distinção lógica de princípios e regras, bem como consideram que os princípios estariam de certa forma envoltos nas regras, de modo que as regras devem ser afastadas quando afrontarem princípios (ZANON JÚNIOR, 2015). Outrossim, essa aplicabilidade de princípios teria por base uma axiologia prévia conformada num sistema de valores pretensamente universais.

Mas o que de perto chama a atenção é o compartilhamento, em traços gerais, de uma filosofia de matiz liberal. Ferrajoli adota a ressalva liberal de que ao Estado não se deve permitir a intervenção nas decisões e modelos de vida, o que faz mediante a advertência de que se deve assegurar a máxima efetividade aos avanços decorrentes do Estado social, para o quê a construção de uma dinâmica constitucional mostra-se elementar (AVILA, 2017). Na mesma esteira, Dworkin se propõe como liberal, tanto pela advertência de que o Estado trata a todos como iguais à medida que igualmente respeita os vários modelos de vida, do que resulta a axiologia oficial da neutralidade, como pela epistemologia jurídica que adota, no sentido de que a interpretação do direito revela-se séria enquanto coerente, o que reivindica o esforço de argumentação sob o elemento integrador "da igualdade" na roupagem liberal da igual consideração aos vários modelos de vida boa (AGUILHERA PORTALES, 2015).

A pressuposição do conteúdo material da igualdade como igual dignidade das individualidades constitui ponto comum a ambas as teorias. Se para Ferrajoli esta se realizaria na impossibilidade de o Estado interferir de forma ilegítima, isto é, de tomar a decisão por quem não a pode tomar ou de decidir sobre aquilo que não pode decidir, para Dworkin as limitações ao Estado também consubstanciam preocupação elementar em sua obra, cujo eixo central gravita no condicionamento das atuações legítimas de governo, ainda que sob justificativa na vontade da maioria, à igual consideração aos vários modelos de vida, de maneira que a "democracia", quando compreendida pelo processo político, estaria limitada pelo núcleo essencial que resguarda a igual dignidade das individualidades.

Não obstante, é importante que se ressaltem as diferenças, cuja maior relevância, no plano teórico, encontra-se na relação entre direito e moral. Para as teorias garantistas, ao menos por uma formulação linguística, o direito e a moral devem se manter separados. A primeira consistiria apenas no conteúdo material do direito, quando justificável mediante interesse público (BARRETO, 2016). Entretanto, a ideia de um distanciamento teórico entre o direito e a moral não eximem o pensamento filosófico (MELO; POMPEU, 2017). A filosofia parte como paradigma para indicar o quão jurídica vai ser a moral, diante das limitações possíveis de Estado, de modo que mesmo diante da diferença mantém-se a lógica e a integralidade do sistema. 
Ronald Dworkin, por sua vez, trata o direito a partir da moral. Desde escritos anteriores, como império do Direito, Dworkin trabalha o elemento epistemológico "integrador" como metodologia adequada à prática do direito: integridade de princípios. Referido elemento, por sua vez, já possuía conteúdo material, a flertar com a concepção da igualdade como igual relevância dos vários modelos de vida. É bem verdade que, nesse primeiro momento, a epistemologia da integridade de princípios, bem como o seu conteúdo material, eram compreendidos como uma forma específica de a comunidade política norte-americana se ver e conceber.

Não obstante, por ocasião do seu penúltimo livro, Justice for Hedghogs, Dworkin adota a perspectiva metafísica da axiologia liberal: ela seria inerente à pessoa e não a uma cultura. A pessoa teria dois deveres morais elementares à sua dignidade: o auto respeito e a autenticidade (DWORKIN, 2011). Ou seja: ela deveria levar a sua vida a sério - e não a tratar como oportunidade desperdiçada -, o que faz pela construção de uma narrativa de vida coerente aos seus valores elementares. Essa construção metafísica da pessoa, de outra sorte, é elemento que se reputa como herança mais fortemente Kantiniana do que jusnaturalista. À exemplo de Kant, Dworkin confere ao direito caráter fundamentalmente antropológico, uma vez que o concebe e o molda em adequação ao dever moral elementar à pessoa racional: mas enquanto em Kant o dever moral se revela nos imperativos categóricos, em Dworkin se manifesta na dimensão existencial de se construir uma vida de forma coerente ao que efetivamente se valoriza.

Outro aspecto relevante é que Dworkin, sobre a justice for Hedghogs, adverte que o ouriço sabe de uma única coisa, mas "o" essencial: o elemento integrador das coisas. Esse elemento, para Dworkin, que limita, condiciona, inspira e justifica os institutos sociais, tais quais o direito, a economia, o mercado, o processo político, apresenta conteúdo axiológico específico, conforme já se falou. Aqui, a moral e a filosofia são prévias ao direito: não são um elemento da teoria do direito, como o é para as construções de matiz positivista. Para o norte americano, repita-se, a moral estaria a balizar o direito, sobretudo naqueles casos difíceis, pelos quais a lei e o precedente revelam-se insuficientes (KYRITSIS, 2016).

É importante que se chame a atenção para o ponto que acima se iniciou a tratar: diferentes condutas epistemológicas sobre direito e moral. Na teoria do garantismo, sobressai o positivismo como sistema de legitimação: a moral é elemento que até pode justificar o direito, mas não o integra per si. A filosofia integra a teoria geral do direito. Ela seria compreendida por uma perspectiva jurídica ${ }^{3}$. Já Dworkin, e isto desde o início de suas obras, trabalha uma teoria de superação do positivismo ou da prática jurídica a qual ele denomina de semântica. Abstraindo-se da modulação de uma dinâmica de legitimação e validação, Dworkin adota a perspectiva epistemológica de que o direito é interpretação, que se deve realizar a partir de um elemento axiológico integrador: a moral consubstanciada na igual dignidade das individualidades. Mas essa íntima relação entre moral e direito, é importante que se ressalte, não estaria envolta em liberdade absoluta ou em discricionariedade por parte do julgador. As decisões dos hard cases passa mormente pela escolha da melhor decisão possível, ou seja,

3 Em aula na disciplina de Filosofia do direito, na Faculdade de Direito da Universidade de Lisboa proferida no dia 02 de março de 2018, o Professor Catedrático Fernando Borges Araújo, ao tratar do jusnaturalismo e positivismo, abordou a questão referente ao relacionamento entre direito e filosofia, ao indagar se a filosofia, ao ser aplicada ao direito, deve ser tratada por juristas ou se mantém autonomia referente ao direito. A partir de suas considerações, realiza-se a presente análise comparativa entre Dworkin e Ferrajoli, 
aquela que mediante uma argumentação séria represente a "melhor escolha" dentre as possíveis decisões legítimas ao caso (MARINHO, 2017). E o conhecimento de uma filosofia que não é colonizada pelo direito revelar-se-ia em absoluto necessário para a construção dessa interpretação séria, que se mostra a correta à medida que se mantenha coerente diante dos vários argumentos contrafactuais.

Não obstante uma formulação aparentemente distinta do direito, o positivismo muito se tem aproximado da moral. Veja-se: ainda que o garantismo, na sua perspectiva positivista, insista na legitimação da norma por uma epistemologia formal, a adequação à matéria e à forma prescrita nas normas superiores pelas de hierarquia inferior, a ênfase na adequação material, em especial quando a Constituição adota princípios morais de abertura semântica, implica um diálogo intenso entre moral e direito. 0 Direito se vai construindo sobre princípios morais, não apenas em uma perspectiva de justificação prévia, apriorística, mas a incorporando ao seu conteúdo. Nestes termos, a prática do garantismo não se distingue, elementarmente, da teoria interpretativa do direito adotada por Dworkin, não obstante diferente a formulação teórica sobre o relacionamento entre direito e moral.

\section{CONCLUSÁO}

O presente trabalho teve por objetivo trazer teorias diferentes e usuais no discurso da prática jurídica, para o que se tomou por elementos paradigmáticos os escritos de Ronald Dworkin e Luigi Ferrajoli, com o objetivo de explicitar as semelhanças e diferenças e compreender as concepções epistemológicas do direito que marcam as práticas jurídicas da contemporaneidade.

Ronald Dworkin, relatou-se no decorrer deste artigo, impactou a jusfilosofia com a construção de uma teoria interpretativa do direito baseada em argumentos axiológicos da ordem liberal. Ao adotar uma base axiológica fundamentada na igual dignidade dos vários modelos de vida que inspira, condiciona e legitima a intervenção estatal, Dworkin demonstrou não apenas a compatibilidade, como também a imprescindibilidade do mercado e do processo político democrático como instrumentos de realização dessa axiologia liberal.

A teoria dworkiana, em sua grande parte, foi-se formulando mediante a análise de casos concretos, o que já implicava o esforço pela argumentação jurídica séria como critério de realização do direito. Revela, por outro lado, a sua cultura estadudinense informada pelo common law. Nesta metodologia, abstrai-se de trabalhar um modelo fechado de legitimação e validação do direito: Dworkin contrapôs-se à teoria positivista do direito ao concebê-lo como prática interpretativa que se realiza pelo método da integração de princípios - abandona, por via de consequência, a concepção do pragmatismo e convencionalismo. Ronald Dworkin, é bom que se frise, trabalha o direito como empresa interpretativa de vários dados apriorísticos, Constituição, leis, precedentes, sob o esforço da coerência e fidelidade a revelar-se na integração de princípios como metodologia a melhor construir uma solução para o caso concreto.

Já Luigi Ferrajoli construiu a teoria do garantismo. Do plano epistemológico, tal teoria é formulada como uma teoria geral do direito, no contexto democrático que encontra na filo- 
sofia política a justificativa para o modelo de centralização e hierarquia das normas constitucionais como primado liberal de proteção e tutela de direitos. Dessa forma, o garantismo não despreza uma axiologia filosófica, já que a incorpora como elemento de interpretação do direito e limitação do estado: mas o faz de forma colonizada a um modelo pré-concebido de validação e realização do direito. Talvez assim o faça porque as ideias garantistas foram formuladas num contexto de países que adotam como metodologia jurídica um sistema rígido de legalidade.

O compartilhamento de uma filosofia liberal norteada pela individualidade, o que demanda proposições de limitação e legitimação do Estado, revela que as aspirações liberais de igualdade e liberdade têm informado, axiologicamente, o direito, o que, ao se confirmar em outras análises comparativas, servirá de importante elemento aos cultores do aspecto cultural como fonte legitimadora da prática jurídica. Não obstante, os dois autores investiram em diferentes discursos metodológicos. O Garantismo apresenta traços do positivismo, no esforço de adequá-lo ao pós-constitucionalismo, ao passo que Dworkin rejeita, por completo, a perspectiva positivista do direito, ao qual ele atribui um esforço semântico de descoberta e explicação de um fato em contraposição a uma empresa interpretativa, que seria a verdadeira essência do direito. Entretanto, o garantismo, ao insistir na adequação material como elemento de legitimação e validação das normas, no contexto de positivação de valores, traz a moral para dentro do direito, a incorpora à prática jurídica. Portanto, de se investir no garantismo ou na integridade de princípios, deve-se abrir para um conhecimento sério e responsável da filosofia, que não raro servirá como última instância argumentativa do direito. O estudo da filosofia, não apenas como apêndice da teoria geral do direito, mas no seu sentido amplo, mina o subjetivismo cujo cavalo de Tróia, em não raros os casos, apresenta-se na figura de princípios de abstração semântica que propiciam interpretações sem substância.

É preciso que se eleve a filosofia a um patamar relevante na vivência jurídica, de maneira que se realize uma prática jurídica responsável, o que se avalia pela qualidade da argumentação. Na prática, portanto, a distinção entre o exercício do positivismo e o da integridade de princípios vai perdendo muito da sua nitidez; não obstante, a manutenção de diferentes discursos ainda revela diferenças empíricas relevantes, em especial no tocante à fundamentação. O positivismo, ao insistir num sistema formal e fechado de validação e legitimação do direito por uma cadeia normativa hierárquica, limita o alcance prático da axiologia como elemento fundante do direito: ela vige enquanto incorporada pelas normas jurídicas. Referida perspectiva é especialmente relevante no contexto do direito internacional, quando se debate acerca de uma axiologia universal determinante a todos os povos, independente da sua história e cultura.

De outra sorte, a perspectiva de o direito possuir uma dinâmica hierárquica e formal de legitimação termina por trabalhar uma mentalidade diversa da concepção do direito como empresa interpretativa a partir de uma axiologia prévia. No primeiro caso, a ênfase epistemológica no método de validação e legitimação tende a relegar a filosofia à matéria do direito, já no segundo, a filosofia revela-se essencial e autônoma, já que seria a luz a dar integridade e coerência ao direito. Seja como for, não se pode olvidar da advertência: a filosofia deve ser tratada com devida seriedade e respeito, de maneira que não corrompa a prática jurídica por achismos que terminam por colonizar o direito a modos e pontos de vista particulares. 


\section{REFERÊNCIAS}

AGUILERA PORTALES, Rafael Enrique. Los derechos humanos como triunfos políticos en el estado constitucional: el dilema entre democracia comunitaria y liberal en Ronald Dworkin. Probl. anu. filos. teor. derecho, México, $\mathrm{n}$. 9, p. 377-408, dic. 2015 . Disponível em http://www.scielo.org.mx/scielo.php?script=sci_arttext\&pid=S2007-43872015000100010\&lng=es\&nrm=iso. Acesso em 10 dez. 2017.

AVILA, Jheison Torres. La teoría del Garantismo: poder y constitución en el Estado contemporáneo. Rev. Derecho, Barranquilla, n. 47, p. 138-166, June 2017. Disponível em http://www.scielo.org.co/scielo.php?script=sci_ arttext\&pid=S0121-86972017000100138\&lng=en\&nrm=iso. Acesso em 10 Dez. 2017.

BARRETO, Andrea Sangiovanni. Uma análise crítica do sistema garantista de Luigi Ferrajoli ante o abolicionismo de Louk Hulsman. Revista Liberdades. Jan/abril. 2016. Disponível em: http://www.revistaliberdades.org.br/_ upload/pdf/26/Liberdades21_EscolasPenais01.pdf. Acesso em: 10 dez. 2017.

CADEMARTORI, Daniela; CADEMARTORI, Sérgio. A relação entre Estado de direito e democracia no pensamento de Bobbio e Ferrajoli. Seqüência: Estudos Jurídicos e Políticos, Florianópolis, p. 145-162, jan. 2006. ISSN 21777055. Disponível em: https://periodicos.ufsc.br/index.php/sequencia/article/view/15097/13752. Acesso em: 15 nov. 2016. doi:http://dx.doi.org/10.5007/15097.

CADEMARTORI, Luiz Henrique Urquhart; GRUBBA, Leilane Serratine. O embasamento dos direitos humanos e sua relação com os direitos fundamentais a partir do diálogo garantista com a teoria da reinvenção dos direitos humanos. Rev. direito GV, São Paulo, v. 8, n. 2, p. 703-724, Dez. 2012 . Disponível em: http://www.scielo. br/scielo.php?script=sci_arttext\&pid=S1808-24322012000200013\&lng=en\&nrm=iso. Acesso em 10 Dec. 2017. http://dx.doi.org/10.1590/S1808-24322012000200013.

COSTA, Oswaldo Poll; VERAS NETO, Francisco Quintanilha. GARANTISMO À BRASILEIRA: UMA ANÁLISE CRÍTICA À LUZ DA APLICAÇÃO DO PRINCÍPIO DA INSIGNIFICÂNCIA. Revista da Faculdade de Direito UFPR, Curitiba, PR, Brasil, v. 61, n. 3, p. 165 - 187, dez. 2016. ISSN 2236-7284. Disponível em: http://revistas.ufpr.br/direito/article/ view/46467/29839. Acesso em: 12 ago. 2017.

DIDIER JR, Fredie. Os três modelos de direito processual: inquisitivo, dispositivo e cooperativo. In: Revista de Processo. Vol. 36. n 198. Ago. Brasília: STJ, 2011. P.213-225. Disponível em: http://bdjur.stj.jus.br/jspui/handle/2011/80945. acesso em: 31 ago. 2016.

DWORKIN, Ronald. A virtude soberana - A teoria e a prática da igualdade. São Paulo: Martins Fontes, 2005.

DWORKIN, Ronald. Justice for hedgehogs. Cambridge: Havard University Press, 2011.

DWORKIN, Ronald. Uma questão de princípio. Tradução de Carlos Borges. São Paulo: Martins Fontes, 2000.

FACHIN, Luis Edson. SCHULMAN, Gabriel. CONTRATOS, ORDEM ECONÔMICA E PRINCÍPIOS: um diálogo entre o Direito Civil e a Constituição 20 anos depois. In: Bruno Dantas et. al.. (Org.). Constituição de 1988, o Brasil 20 anos depois. Brasília: Senado Federal, 2008, v. IV, p. 347-377).

FREITAS, Marisa Helena D’Arbo Alves de; MANDARINO, Renan Posella; ROSA, Larissa. Garantismo Penal para Quem? O Discurso Penal Liberal Frente à sua Desconstrução pela Criminologia. Sequência (Florianópolis), Florianópolis, n. 75, p. 129-156, Abr. 2017. Disponível em: http://www.scielo.br/scielo.php?script=sci_ arttext\&pid=S2177-70552017000100129\&Ing=en\&nrm=iso. Acesso em 10 Dez. 2017.

FERRAJOLI, Luigi. Direito e Razão. Teoria do Garantismo Penal. 4ª edição. rev. atual. São Paulo: Revista dos Tribunais, 2014.

GOODHEART, E. Deal or No Deal. Society. 50, 3, 224-229, Junho 2013. ISSN: 01472011.

IPPOLITO, Dario. O garantismo de Luigi ferrajouli. In: Revista de Estudos Constitucionais, hermenêutica e Teoria do Direito (RECHTD), jan-ju.2011. São Leopoldo: Unisinos, 2011.

IOSA, Juan. LIBERTAD NEGATIVA, AUTONOMÍA PERSONAL Y CONSTITUCIÓN. Rev. chil. derecho, Santiago, v. 44, n. 2, p. 495-518, agosto 2017. Disponible en http://www.scielo.cl/scielo.php?script=sci_arttext\&pid=S0718-34372017000200495\&lng=es\&nrm=iso. accedido en 09 dez. 2017. 
KYRITSIS, Dimitrios. A New Interpretivist Conception of the Rule of Law. Probl. anu. filos. teor. derecho, México, n. 10, p. 91-109, dic. 2016. disponível em http://www.scielo.org.mx/scielo.php?script=sci_arttext\&pid=S2007-43872016000100091\&lng=es\&nrm=iso. acesso em 09 dez. 2017.

MARCO, Cristhian Magnus; SANTOS, Paulo Júnior Trindade; MOELLER, Gabriela Samrsla. A TEORIA DA JUSTIÇA REVISITADA PELA TEORIA DA INJUSTIÇA: DEMOCRACIA E DIREITO PARA SE FALAR EM JUSTIÇA HOJE. Revista Thesis Juris. V.8 n2. Disponível em: https://periodicos.uninove.br/index.php?journal=thesisjuris\&page=article\&o p=view\&path\%5B\%5D=14832\&path\%5B\%5D=pdf acesso em 20 mar. 2020.

MARINHO, Jefferson L. A. Teoria da integridade de ronald dworkin: um olhar matemático para a tese da resposta correta. Prisma Jur., São Paulo, v. 16, n. 1, p. 75-95, 2017. Disponível em: http://www4.uninove.br/ojs/index.php/ prisma/article/view/7185/pdf_67. Acesso em 17 jan. 2018.

MELO, Rafael Veras Castro; POMPEU, Gina Vidal Marcílio. direito e filosofia: é possível construir uma teoria jurídica coerente sem a reflexão filosófica?. Revista Thesis Juris - RTJ, elSSN 2317-3580, São Paulo, v. 6, n.2, p. 312-327, maio/ago. 2017. Disponível em: http://periodicos.uninove.br/index.php?journal=thesisjuris\&page=article\&op=vi ew\&path\%5B\%5D=9005\&path\%5B\%5D=3839. acesso em 1 abr. 2019.

MONTARROYOS H. Observatório constitucional Ronald Dworkin: reconstruindo o liberalismo do livro "A virtude soberana: a teoria e a prática da igualdade". Universitas Jus [serial online]. January 2013;24(1):89-117. Disponível em: Fonte Acadêmica, Ipswich, MA. Acesso em: 06 dez. 2017.

ROSA, Alexandre Moraes da. O que é garantismo jurídico? Teoria Geral do Direito. Florianopolis: Habitus, 2003.

RODRIGUES, Fernando. Crítica ao positivismo e interpretação. Revista Direito e Práxis. Vol. 4, n. 7. 2013, online, p. 305-318. Disponível em: http://www.e-publicacoes.uerj.br/index.php/revistaceaju/article/view/8351/637.2 acesso em 26 mar. 2018.

SERETTI, Andre P. direitos fundamentais, princípios penais constitucionais e garantismo penal. Revista Direitos Fundamentais \& Democracia. N 17. Jan-2015. Online, 2015. Disponível em: http://revistaeletronicardfd.unibrasil. com.br/index.php/rdfd. acesso em 15 nov. 2016.

VIRGÜEZ RUIZ, S.. DEMOCRACIA, DESACUERDO Y DERECHO CONSTITUCIONAL. UNA REVISIÓN A LA TENSIÓN ENTRE CONSTITUCIONALISMO Y DEMOCRACIA EN EL DEBATE DWORKIN - WALDRON. (Spanish). Revista De Derecho Público, (35), 1-31.. Online. Disponível em: https://derechopublico.uniandes.edu.co/index. php?option=com_content\&view=article\&id=541\%3Ademocracia-desacuerdo-y-derecho-constitucional-una-revision-a-la-tension-entre-constitucionalismo-y-democracia-en-el-debate- $d$ workin-waldron\&catid $=42 \% 3 \mathrm{~A} 3$ 5\&ltemid=132\&lang=es. acesso em 28 mar. 2020.

ZANON JÚNIOR, Orlando Luiz. GARANTISMO JURÍDICO: O ESFORÇO DE FERRAJOLI PARA O APERFEIÇOAMENTO DO POSITIVISMO JURÍDICO. REVISTA DA ESMESC, v. 22, n. 28, p. 13-38, 2015.

Recebido/Received: 01.06.2020.

Aprovado/Approved: 09.07.2020. 